\title{
La cultura nacional: problema y posibilidad*
}

\author{
Antonio Cornejo Polar \\ Todo hombre no embrutecido \\ por el egoísmo puede vivir, \\ feliz, todas las patrias. \\ JosÉ MARÍA ARguEDAS
}

Puesto que mi especialidad es la crítica literaria. mi exposición va a tener esa perspectiva central, pero espero que esta perspectiva especializa$\mathrm{da}$, y en esa misma medida recortada, pueda incorporarse al horizonte de la reflexión general sobre el problema de la cultura nacional en el Perú.

Me interesa partir haciendo un brevísimo recuento de cómo el concepto de literatura nacional, y por extensión de cultura nacional, ha sido materia de una serie de ideologizaciones, especialmente de ideologizaciones que reproducen y tratan de convalidar los intereses de las clases dominantes. Yo creo que el principio de este proceso ideológico consiste en afirmar como axioma que no se puede hablar de cultura nacional, y por consiguiente tampoco de literatura nacional, si previamente no se asegura la vigencia de la categoría de unidad. Así, entonces, el problema nacional fue planteado indebidamente, como si todo se redujera a saber si ya somos culturalmente una unidad, si estamos en trance de serlo o cómo conseguir, a través de qué caminos, ese objetivo. Habría que señalar rápidamente que esta asociación entre nación, cultura nacional y unidad tiene su raíz en la experiencia europea relativa a la formación de los estados nacionales ( $y$ se puede añadir lo que es obvio: que esa experiencia tiene poco que ver con la peculiaridad histórica de nuestros países).

Es muy curioso, pero también muy significativo, rastrear cómo se conseguía elaborar esta imagen de unidad cuando todos sabíamos que en la realidad de las cosas lo que existía era todo lo contrario: multiplicidad, di-

* Publicado por Lluvia Editores (Lima, 1981).

LETRAS (Lima), 94: 121-129,1997. 
versidad, contradicciones. Por ejemplo, en las primeras reflexiones sobre la literatura peruana, concretamente en el pensamiento de Riva-Agücro, se obtiene la imagen de la unidad de la manera más expeditiva posible. Lo que hace Riva-Agüero simplemente es quitar, borrar del espacio nacional todo aquello que no coincidía con su muy curiosa idea del Perú como país hispánico. En otras palabras: todo lo que no tiene carácter hispánico queda fuera de la nación, incluyendo lo indio que para él era (¡y lo dice expresamente!) un componente exótico, ajeno al verdadero Perú. Imagina que el sustrato indio irá desapareciendo paulatinamente y que entonces el país quedará libre de esa carga y podrá ser el país blanco con que el que soñaba. Entonces ¿cómo logra Riva-Agüero constituir su imagen de unidad? En el caso de la literatura, expulsando del espacio de la literatura nacional a todas las literaturas en lenguas nativas y también a la literatura popular. Porque hay que recordar que para Riva-Agüero no sólo se trata de borrar lo indio para quedarse sólo con lo español, sino también de suprimir lo popular para quedarse sólo con lo que se llama, entre comillas, "culto"; es decir, aquello que coincide con las normas y valores de la cultura oecidental. Creo que está claro que en este caso la imagen de la literatura peruana como una literatura de raíz, forma y espíritu hispánicos es el producto de una mutilación y que esa mutilación reproduce con bastante exactitud el proyecto y los intereses sociales de la vieja oligarquía peruana, la que -como decía Mariátegui- desciende de los encomenderósespaños. Letras

\section{"Jorge Puccinelli Converso"}

Esto quiere decir que el concepto que Riva-Agüero expone sobre la literatura peruana no es distinto del concepto que tiene sobre el Perú en general y ese concepto (en realidad esa ideología) no es más que la trasposición a un plano específico de la superestructura de un orden social perfectamente real (y también perfectamente injusto, por cierto). Después de todo para la vieja oligarquía el Perú todo se confundía con el vértice de la pirámide social y ese vértice estaba ocupado por la clase y la etnía dominante. Lo demás, aunque ese "demás" incluyera una inmensa mayoría de la población, sobraba, incomodaba, tenía que suprimirse. Habría que recordar que por entonces Deustua decía que era absurdo pensar que el indio podía ser algo más que una máquina...

Ahora bien: es evidente que un procedimiento tan simple, en el fondo tan brutal: eliminar lo que molesta, quitar lo que incomoda, negar todo valor a lo que no se parece a uno mismo, no podía mantenerse por mucho 
tiempo. Por lo menos en el plano científico era imposible mantener por mucho tiempo una aberración tan grande. La manipulación era tan obvia que cualquiera podía darse cuenta que detrás de esos juicios no había ciencia sino pura ideología, la ideología de la clase-casta dominante. Por eso hay un segundo momento, distinto al anterior, que rectifica las tesis de Riva-Agüero mediante el empleo de otra categoría: la del mestizaje, como categoría que trata de invalidar la categoría de lo hispánico.

Yo creo que el problema del mestizaje es uno de lo más confusos. Por lo pronto me parece que hay que distinguir claramente entre el mestizaje real y la ideología del mestizaje, que es una cosa completamente distinta. Tal vez viendo cómo juega el concepto de mestizaje en la crítica peruana pueda entenderse mejor este asunto. Hay que decir, en primer lugar, que la idea de mestizaje no es de ninguna manera uniforme. Para el caso de la literatura podemos mencionar dos, hasta tres acepciones distintas de la palabras mestizaje. Por ejemplo, Gályez afirmaba que la cultura peruana, y nuestra literatura específicamente, tenía que ser mestiza para poder ser genuina, pero él entendía que este mestizaje estaba constituido por una firme base hispánica y algunos pocos ingredientes de origen indígena; es decir, un mestizaje desbalanceado y desarmónico (que sin embargo representa un adelanto con respecto al purismo hispánico anterior). En cambio Federico More, que emplea el mismo concepto, entiende por mestizajęractamente lo opuesto; esto es, una base indígenay alıunos componentes bispánicos, considerando además que en esa base, en la tradición quechua o aymara, reside lo más propio de la nacionalidad. En términos generales los planteamientos de More representan el pensamiento del grupo indigenista, especialmente el de Puno, mientras que los de Gálvez son representativos más bien del grupo criollista, especialmente el criollismo limeño.

Hay que darse cuenta, entonces, que Gálvez y More representan dos alternativas distintas, pero al mismo tiempo hay que tener conciencia que ambas, cada una a su manera, insisten en ver la nacionalidad, concretamente la literatura nacional, como una unidad. Ahora, esa unidad es producto de la síntesis del mestizaje, aunque ese mestizaje pueda ser internamente, por un lado u otro, muy desarmónico. En todo caso se repite la idea de asociar nación a unidad. Tal vez la expresión más extrema de esta tesis sea la de Sánchez. En su polémica con Mariátegui, Sánchez propugnaba lo que él llamaba el "peruanismo totalista", que en realidad es una pura abstracción, totalmente 
irreal, según la cual la síntesis del mestizaje sería de un 50\% hispánico y del otro $50 \%$ indígena. Naturalmente así se refuerza la idea primaria de la unidad: una unidad absolutamente perfecta en este caso, pero -por supuesto-irreal.

Tengo para mí que las ciencias sociales y la historia de las ideas encontrarían un tema riquísimo estudiando la ideología del mestizaje. Como dije hace un momento, una cosa es el mestizaje, que es una realidad en la que todos estamos inmersos, y otra muy distinta la ideología del mestizaje. Mediante esta ideología lo que se postula frecuentemente es que bastaría la realización del mestizaje para que que se resolvieran los problemas básicos del Perú y de su cultura. En este sentido la ideología del mestizaje es en antropología lo que sería la ideología de la conciliación de clases en la sociología. Después de todo también el mestizaje como síntesis no conflictiva, como armonía entre grupos étnicos que en la realidad tienen relaciones de dependencia y opresión, es una forma de imaginar la conciliación por encima de los conflictos reales. A yeces se tiene la impresión de estar frente a una resurrección del neoplatonismo y de su afirmación central acerca de la armonía de los contrarios...

Evidentemente la ideología del mestizaje puede expresar también una visión oligárquica (recuérdese a Chocano afirmado su doble ancestro imperial, inkaico y español), pero mâs claramente exprosa la ideología de una burguesía en ascenso quetiene que tratar derepresentar a otras clases, a las que a su vez subordina, para legitimar su poder frente a la vieja oligarquía hispanizante. Es una representación en último término más simbólica que real, y finalmente inocua, pues poco ganan las etnías oprimidas con ser recibidas, como un matiz aleatorio, en la imagen que otras clases y etnías tienen del Perú. Habría que señalar también que la influencia de esta ideología es tanta que inclusive mucha gente sin compromiso con la burguesía la adopta como propia. Al parecer tiene el encanto de todas las imágenes apacibles, armoniosas, no conflictivas. Lástima que la realidad sea lo contrario, exactamente lo contrario.

Con José Carlos Mariátegui cambia radicalmente el rumbo de la reflexión sobre el problema de lo nacional en el Perú, incluyendo la reflexión sobre la literatura nacional peruana. Creo que Mariátegui es el primero en cuestionar la legitimidad y la pertinencia de la categoría de unidad como supuesto indispensable para pensar los problemas de la nacionalidad. Como 
verdadero científico, Mariátegui no inventa una realidad, no ideologiza, sino que obeserva esa realidad y trata de explicarla, de encontrarle un sentido; pero además, como científico revolucionario, ese conocimiento lo convierte en praxis y lo proyecta hacia la transformación y cambio de la realidad. Me parece que la izquierda peruana debería poner más énfasis en señalar el carácter científico del pensamiento de Mariátegui y no quedarse, como suele suceder con frecuencia, en la afirmación de su corrección político-ideológica.

Pues bien: volviendo al campo de la literatura Mariátegui señala, casi al comenzar su "Proceso de la literatura", que como recuerdan es el último de sus 7 ensayos, que la literatura peruana es una literatura no orgánicamente nacional. Y con esta frase que lamentablemente quedó desapercibida por la crítica posterior, Mariátegui fundó una nueva posibilidad de entender nuestra literatura (que por supuesto está en relación con una manera de entender al Perú en su conjunto). Por lo pronto, al afirmar el carácter no orgánicamente nacional de nuestra literatura, Mariátegui abre la posibilidad de considerar otros sistemas literarios, y no sólo el cuíto en español, dentro de las literaturas (ahora en plural) que se producen en el Perú.

Aquí habría que analizar varios aspectos. Por lo pronto . Mariátegui acaba con la necesidad de șustentar 1 nacional sobre la base de la categoría de unidad, pues de hecho acepta que nuestraliteratara es múltiple, plural, que en la realidad existegvarioscsistemais literatios,ocultos y populares, en español, en quechua o en aymara, y evidentemente ninguno de ellos puede ser rechazado: todos son parte de la literatura nuestra, de la literatura peruana. Acepta pues los hechos: desarticulación, desmembración, ruptura y hace precisamente de esas categorías los instrumentos adecuados para conocer, tal como efectivamente es, nuestro múltiple rostro literario (por extensión nuestro múltiple rostro social y cultural). Acaba esa imagen engañosa de la unidad, un verdadero fantasma que obligaba a tergiversar todo nuestro proceso literario y en el fondo toda nuestra realidad y a tergiversar todo nuestro proceso literario y en el fondo toda nuestra realidad y a tergiversar todo esto en función -como hemos visto- de la ideología y de los intereses de las clases dominantes.

Entonces, a partir del planteamiento de Mariátegui, se puede comenzar a estudiar y tratar de comprender este objeto múltiple, hecho de quiebras y contradicciones, y ya no tenemos por qué suponer que esa variedad cultural (y literaria) 
es negativa, casi una desgracia, como si la pluralidad fuera causa única de nuestro atraso y de todos nuestros problemas. Es al revés, al aceptar la pluralidad nos enriquecemos y además somos fieles a lo que efectivamente somos. Porque si seguimos pensando en la unidad e imaginamos que en este momento Vargas Llosa está escribiendo una novela y un narrador popular está contando en quechua un cuento a sus oyentes, entonces, si seguimos aceptando la unidad, tendríamos que convenir en que sólo una de las dos situaciones corresponde a la literatura peruana y la otra no, porque, como es claro, se trata de dos prácticas completamente distintas, pero si rompemos el mito de la unidad entonces podemos decir que las dos son verdaderamente literatura (es decir, ambas tienen valor estético) y además podemos afirmar que ambas son literatura peruana (es decir, nos corresponden socialmente, nos representan). Ambas son legítimas. Y si esto es así entonces cambia toda nuestra imagen de la literatura peruana: ahora podemos imaginarla como un hervidero de creatividad, en español, en quechua, en aymara, en las lenguas de selva. Evidentemente la pluralidad no ha acabado con nuestra literatura; al revés, la ha enriquecido notablemente.

Sería ahora el momento de recordar que otro peruano ejemplar, que siguió la ruta de Mariátegui aunque en otro terreno, el específicamente literario; sería el momento de recordar -repito- que José María Arguedas dijo alguna vez una frase que podría sintetizar lo dicho hasta aquí. Dijo en ese estremecedor "Diario"' que intercala en Su últimatrovela, en El zorro de arriba y el zorro de abajog que en êl Berú (y crearque la cita es casi literal) todo hombre no embrutecido por el egoísmo puede vivir, feliz, todas las patrias, Si: "todas las patrias"; como antes, el mismo Arguedas, había titulado a su novela más ambiciosa con un nombre del mismo significado: Todas las sangres. Arguedas era también un defensor de la pluralidad. Por esto, en El zorro... con mucho humor, dice que si en el Perú todos fuéramos iguales, si hubiera esa unidad que antes tan afanosamente se buscaba, entonces, si no hubiera pluralidad, todo esto sería pura "huevadez humilde"...

Hay que subrayar que reconocer la pluralidad que es el Perú es reconocer el derecho de las culturas oprimidas a seguir siendo culturas diferenciadas, a seguir manteniendo en pie su identidad; su derecho a defender de la dominación y la alienación con que se les quiere liquidar o asimilar, siempre en inferioridad de condiciones, dentro de la cultura dominante. Que no se diga entonces que para que el Perú sea uno, una verdadera nación, las culturas oprimidas tienen que desaparecer. La gran virtud de los plantea- 
mientos de Matiátegui y Arguedas es que nos hacen ver que si bien es cierto que la pluralidad entendida como disgregación puede crear problemas ( $\mathrm{y}$ de hecho los crea), no por eso vamos a liquidar lo que es, desde otro punto de vista, nuestra riqueza. Después de todo la pluralidad es una opción de riqueza, una opción de plenitud, una opción de humanidad y de universalidad. Y aun si no fuera así: ¿con qué derecho los miembros de una cultura van a exigir a los de otra cultura que dejen de ser distintos? Ciro Alegria decía que a veces lo que se llama "barbarie" es la verdadera civilización; se preguntaba quién es bárbaro ¿el indio que pide una escuela o el "blanco" que se la niega? Y alguna vez, jugando un poco con las palabras, dijo Alegría un frase en la que habría que pensar. Refiriéndose al protagonista de El mundo es ancho y ajeno, el anciano y analfabeto Rosendo Maqui, dijo que había también la admirable sabiduría de los ignorantes... Habría que pensar en eso.

Supongo que estamos de acuerdo en que la imagen del Perú plural es más rica y más correcta que la imagen del Perú único y que lo mismo puede decirse con respeto a nuestra literatura. Entonces el problema es saber cómo estudiamos y comprendemos esta pluralidad, cómo nos escapamos de la tradición occidental para pensar en nuestra nación como una multiplicidad. Después de todo: ¿por qué vamos a aceptar que por ser múltiples no somos nación? Lo que sí hay que reconocer es que esa realidad nos obliga a repensar todo lo que concierne å nưestran cultura múltiples a nuestra literatura heterogénea. Es un reţo por supuesto y un reto difícil.

A este respecto quiero apuntar brevemente algunas ideas. Por lo pronto creo que hay que tener muy en claro, cuando se defiende el derecho a la identidad de las culturas oprimidas, que esas culturas representan una situación social de injusticia. Quiero decir que no por defender esa identidad vamos a terminar defendiendo la oprobiosa situación social que las condiciona. La identidad cultural no es nunca algo estático, sin vida, salvo cuando se trata de culturas muertas, acabadas y fijadas en la historia. Pero este no es el caso del Perú. Por consiguiente de lo que se trata es de defender esa identidad cuando se pretende sojuzgarla desde arriba, por medio de la dominación de unos grupos sobre otros, pero evidentemente hay que propiciar el cambio creador cuando nace de sus propias fuentes y se integra dentro de un proyecto de liberación social.

Por otra parte, el concepto de pluralismo no puede hacernos pensar que todas las formas de cultura que efectivamente se producen en el Perú 
son igualmente nacionales. También en este punto podemos seguir el magisterio de Mariátegui. El decía que la literatura peruana pasa por tres etapas: una colonial, otra cosmopolita y una tercera nacional. Es claro que la contradicción básica es entre la primera y la última, si se quiere entre la cultura colonial o neocolonial y la cultura nacional. Esto quiere decir que hay una cultura y una literatura que aunque se producen en el Perú son profundamente antinacionales porque representan y ponen en circulación intereses no sólo ajenos sino opuestos a los verdaderos intereses del Perú. Los sociólogos y los economistas han demostrado fechacientemente que hay clases nacionales y clases antinacionales, como es la burguesía intermediaria que con toda evidencia defiende los intereses del imperialismo y ataca los intereses peruanos. En este sentido la cultura que estas clases crean, incluyendo su literatura, es antinacional. De aquí que Mariátegui asociara siempre el término nacional con el término popular, porque en última instancia es en lo popular donde se eneuentra el verdadero rostro de lo nacional.

En este orden de cosas habría que seguir la dinámica del siguiente raciocinio; primero cuestionaremos la idea de la unidad nacional porque era falsa y porque a través de ello se hacía creer que la única cultura peruana era la de las clases dominantes; después propiciamos la idea de pluralidad porque gracias a ella podemos describir correctamente nuestra realidad múltiple y porque de estaminarasamimos comonacionales todas las manifestaciones culturales que se dan en el país. Pero no basta llegar hasta ahí. El tercer paso supone otra operación intelectual a través de la cual determinamos que en una sociedad dividida en clases y grupos étnicos no todas las culturas tendrán el mismo valor con respecto al concepto de nación. Unas son de verdad nacionales y otras no lo son. Después de todo el campo de la cultura no es de armonía; es, como el campo social, de lucha y de contradicciones. Me parece que sin este tercer momento los dos anteriores no son suficientes y hasta podrían resultar peligrosos, confusos, equivocados. A veces la media verdad es peor que el error. En este caso el concepto de pluralismo sin una calificación social; es decir, como un espacio indiferenciado donde todo da más o menos lo mismo, sería un error. Esa calificación social es indispensable.

Por otra parte, el concepto de pluralismo tampoco nos debe llevar a una simple atomización de nuestra cultura, como si cada una de sus distintas manifestaciones fueran entre sí totalmente independientes. Es decir: son inde- 
pendientes, como en el ejemplo de Vargas Llosa y el narrador popular, en el que cada uno actúa sin tener la menor relación con el otro, sin conocerlo siquiera, pero no son independientes porque ambos, aunque muy distintos, participan de un mismo proceso histórico, un proceso histórico que afecta y condiciona a los dos, aunque por supuesto de distinta manera. Así entonces, aunque no tengan relaciones concretas entre sí, las distintas culturas participan de un mismo curso histórico, que es la historia social del Perú. Pongamos un ejemplo: hay una literatura de la Conquista que es española y otra completamente distinta que es la literatura quechua alusiva a los mismos hechos. Evidentemente no hay relaciones concretas entre ambas, que están incomunicadas, pero una y otra se constituyen en respuesta a un mismo acontecimiento histórico. Ese acontecimiento -en este caso la Conquista-explica los caracteres internos de las dos, pero también explica su contradicción; esto es, permite comprender el conjunto contradictorio que forman las dos.

Ya llamaría a esto totalidad concreta, totalidad histórica, totalidad conflictiva. Y propondría que la pluralidad de la cultura y la literatura peruana fuera entendida en estos términos: son muchas sus variantes, pero todas se explican, en última instancia, en una historia, la historia social del Perú. Se comprenderá que el conceptode totalidad no inhibe las contradicciones; al revés, la totalidad a que aludimos está hecha de contradicciones, sin ellas no existiría, de la mismă maherả queana sociedadestá hecha de las contradicciones entre sus clāses. Son muchas las clases $_{3}$ hay una pluralidad de clases, pero hay una sola sociedad. De la misma manera hay una pluralidad de culturas pero todas las culturas mediante sus relaciones de contradicciones, forman una totalidad. Creo que esta es una categoría que puede explicar la índole profunda de la cultura peruana. Después de todo la cultura nacional no puede ser menos conflictiva, menos contradictoria, que la sociedad que la produce. Así, con este concepto de totalidad, podemos volver a repetir, pero ahora con un sentido tal vez más correcto, esa hermosa frase de Arguedas: en el Perú cualquier hombre no embrutecido por el egoísmo, puede vivir, feliz, todas las patrias. 